\title{
C-Reactive Protein 2 Days After Laparoscopic Gastric Bypass Surgery Reliably Indicates Leaks and Moderately Predicts Morbidity
}

\author{
Rene Warschkow • Ignazio Tarantino • Patrick Folie • \\ Ulrich Beutner • Bruno M. Schmied • Philipp Bisang • \\ Bernd Schultes • Martin Thurnheer
}

Received: 9 January 2012 / Accepted: 22 March 2012 / Published online: 13 April 2012

(C) 2012 The Society for Surgery of the Alimentary Tract

\begin{abstract}
Background The aim of the present study was to evaluate whether serum C-reactive protein (CRP) is a useful predictor of early post-operative complications, particularly of intestinal leaks after laparoscopic Roux-en-Y gastric bypass (LRYGB) surgery.

Methods The present study was a retrospective analysis of a prospectively maintained database with 809 patients who underwent LRYGB from 2002 until 2011. For 410 of these patients, at least one CRP measurement within the first seven post-operative days was available. The diagnostic value was determined by the area under the curve (AUC) of the receiver operating characteristic (ROC) curve.

Results Forty-nine of 410 patients (12.0\%; $95 \%$ confidence intervals [95\% CI], 9.2-15.5\%) developed surgery-related complications. Leaks occurred in 17 patients $(4.1 \%$; $95 \%$ CI, 2.6-6.5\%) at a median of 5 days after surgery. CRP levels 2 days after surgery showed the highest diagnostic value for post-operative complications (AUC, 0.74; $95 \%$ CI, 0.60-0.89). Sensitivity was 0.53 (95\% CI, 0.31-0.74) and specificity was 0.91 (95\% CI, 0.79-0.96) on day 2 (cutoff level, $229 \mathrm{mg} / \mathrm{l})$. The sensitivity for intestinal leaks was 1.00 (95\% CI, 0.51-1.00).

Conclusion CRP on post-operative day 2 is a valuable predictor of post-operative complications, in particular intestinal leaks. Radiological imaging studies for intestinal leaks could be restricted to patients with CRP values exceeding $229 \mathrm{mg} / \mathrm{l}$.
\end{abstract}

Keywords Laparoscopic Roux-en-Y gastric bypass ·

Post-operative complication $\cdot$ Leak $\cdot \mathrm{C}$-reactive protein

\section{Introduction}

Gastric bypass procedures for morbidly obese patients are associated with a considerable morbidity. ${ }^{1}$ Especially,

R. Warschkow $(\bowtie) \cdot I$. Tarantino $\cdot$ P. Folie $\cdot$ U. Beutner $\cdot$

B. M. Schmied $\cdot$ P. Bisang $\cdot$ B. Schultes $\cdot$ M. Thurnheer

Department of Surgery, Kantonsspital St. Gallen,

9007 St. Gallen, Switzerland

e-mail: Rene.Warschkow@kssg.ch

\section{R. Warschkow}

Institute of Medical Biometry and Informatics,

University of Heidelberg,

69120 Heidelberg, Germany intestinal leaks can have serious consequences leading to an increased mortality. ${ }^{2}$ Early detection of these complications is extremely important since timely treatment improves the clinical outcome and reduces mortality. ${ }^{3-7}$ Many bariatric surgeons routinely perform upper gastrointestinal (GI) series to detect anastomotic problems in time..$^{8-13}$ However, the diagnostic value of the upper GI series is quite limited; thus, some authors propose a more selective strategy using the upper GI series only on clinically symptomatic patients. ${ }^{10-12,14-16}$

It has been demonstrated that the post-operative Creactive protein (CRP) serum level can predict septic complications after open visceral operations, such as colorectal, gastro-oesophageal and pancreatic surgery. ${ }^{17-22}$ The serum CRP level on post-operative day 4 (POD 4) has consistently been found to have the best diagnostic value using cutoff levels around $140 \mathrm{mg} / \mathrm{l} \mathrm{CRP}$. CRP measurements are relatively inexpensive, widely available and clinically well- 
established. ${ }^{23-25}$ However, little is known about CRP as a predictor of complications after laparoscopic procedures. Therefore, we performed a study assessing the predictive value of CRP levels for general post-operative complications and especially intestinal leaks after laparoscopic Roux-en-Y gastric bypass (LRYGB) surgery.

\section{Material and Methods}

\section{Study Design and Endpoints}

This study was a retrospective diagnostic cohort study including all severely obese patients operated on with a LRYGB procedure between January 1, 2002 and February 28, 2011 at our institution. Data were derived from a prospectively maintained database. Serum CRP level was evaluated as predictor for 30-day morbidity and intestinal anastomotic leaks.

\section{Study Outcome Measures and Definitions}

Post-operative mortality was defined as any death within 30 days after surgery. Study outcome measures were the following surgery-related complications: leaks of the gastrojejunal and ileo-ileal anastomosis, staple line leaks, stenosis, bleeding, ulcers of the gastrojejunal anastomosis, the ileoileal anastomosis and the remnant stomach, intra-abdominal bleeding, internal and trocar site hernias, ileus, wound infections and pancreatic injuries. If a patient required surgical revisions, only CRP measurements performed before the revision surgery were included in this study. Intestinal leak was defined as the presence of contrast agent outside of the GI tract in radiology examination or proof of anastomotic leakage upon reoperations. General complications were defined as all non-surgical complications.

\section{Eligibility Criteria for Patients}

Patients with at least one CRP measurement between day 2 and day 7 after surgery were included in the final analysis. The indication for surgery was based on the guidelines of a Consensus Development Conference Panel of the National Institutes of Health and on the Consensus on Obesity Treatment in Switzerland. ${ }^{26,27}$ Patients converted to an open gastric bypass operation as well as patients with previous bariatric surgeries except gastric banding were excluded from the study.

Perioperative Management

All patients routinely received pre-operative antibiotic prophylaxis $(500 \mathrm{mg}$ metronidazole IV and 2,000 mg cefamandole
IV) $60 \mathrm{~min}$ before surgery and a digestive tract decontamination from the day of surgery until radiological control of the anastomosis with a solution of polymyxin $(100 \mathrm{mg})$, tobramycin $(80 \mathrm{mg})$, vancomycin $(125 \mathrm{mg})$ and nystatin $(500 \mathrm{mg})$, administered orally four times a day.

Anticoagulation was achieved with low-molecularweight heparin adjusted for body weight and individual thromboembolic risk according to the patient's clinical history. Between POD 3 and 6, upper GI series were conducted for all patients using an oral water-soluble contrast agent.

Table 1 Distribution and onset of post-operative complications $(n=410)$

\begin{tabular}{|c|c|c|}
\hline & $\begin{array}{l}\text { Frequency, } \\
N(\%)\end{array}$ & $\begin{array}{l}\text { Onset, median } \\
\text { (IQR), days }\end{array}$ \\
\hline Any surgery-related complication & $49(12.0)$ & $4(2-9)$ \\
\hline Leakage of gastro-jejunostomy & $4(1.0)$ & $5(4-7)$ \\
\hline Stenosis of gastro-jejunostomy & $5(1.2)$ & $22(9-30)$ \\
\hline Ulcer of gastro-jejunostomy & $1(0.2)$ & 23 \\
\hline Staple line leak of remnant stomach & $4(1.0)$ & $5(5-5)$ \\
\hline Staple line leak at gastric pouch & $8(2.0)$ & $5(3-7)$ \\
\hline $\begin{array}{l}\text { Total bleeding } \\
\text { Bleeding of gastro-jejunostomy }\end{array}$ & $\begin{array}{r}10(2.4) \\
4(1.0)\end{array}$ & $3(2-9)$ \\
\hline Bleeding of small bowel & $3(0.7)$ & \\
\hline Extra-luminal bleeding & $3(0.7)$ & \\
\hline $\begin{array}{l}\text { Bowel obstruction } \\
\text { Small bowel }\end{array}$ & $\begin{array}{r}10(2.4) \\
5(1.2)\end{array}$ & $4(3-11)$ \\
\hline Jejuno-jejunostomy & $1(0.2)$ & \\
\hline Hernia & $4(1.0)$ & \\
\hline $\begin{array}{l}\text { Perforation } \\
\text { Small bowel }\end{array}$ & $\begin{array}{l}2(0.5) \\
1(0.2)\end{array}$ & $9(4-26)$ \\
\hline Gastric & $1(0.2)$ & \\
\hline Pancreatic complications & $1(0.2)$ & 1 \\
\hline Superficial infection & $4(1.0)$ & $1(1-6)$ \\
\hline $\begin{array}{l}\text { Other complications }{ }^{\mathrm{a}} \\
\text { Treatment of surgery-related } \\
\text { complications }\end{array}$ & $4(1.0)$ & $1(0-10)$ \\
\hline Conservative treatment & $16(3.9)$ & \\
\hline Laparoscopic revision & $13(3.2)$ & \\
\hline Open revision & $20(4.9)$ & \\
\hline $\begin{array}{l}\text { Any general complication } \\
\text { Pulmonary }\end{array}$ & $\begin{array}{l}32(7.8) \\
13(3.2)\end{array}$ & $3(1-7)$ \\
\hline Cardiac & $3(0.7)$ & \\
\hline Allergic reaction & $3(0.7)$ & \\
\hline Neurological & $0(0.0)$ & \\
\hline GI & $4(1.0)$ & \\
\hline Urological & $8(2.0)$ & \\
\hline Other & $1(0.2)$ & \\
\hline
\end{tabular}

$I Q R$ interquartile range

${ }^{a}$ Other $=$ technical failure, abdominal compartment, choledochus stenosis, infarction of spleen 


\section{Surgical Procedure}

One surgeon (MT) performed or at least supervised all procedures. Six ports were placed for the LRYGB procedure. In all patients, a $15-$ to $20-\mathrm{ml}$ gastric pouch was created as the restrictive component. Gut limb lengths were systematically varied according to the patient's body mass index (BMI), co-morbidities, eating habits and psychosocial situation.

\section{CRP Measurements}

Serum CRP concentrations were measured with an automated analytical system (Unicel DxC 800, Beckman Coulter, Brea, CA, USA). The reference range was defined as $<8 \mathrm{mg} / 1$; the detection range was 3-300 mg/l until August 2005, afterwards $3-500 \mathrm{mg} / \mathrm{l}$. For this study, CRP values exceeding $300 \mathrm{mg} / \mathrm{l}$ were reduced to $300 \mathrm{mg} / \mathrm{l}$ to allow comparability of high values from both periods.

\section{Statistical Analysis}

Statistical analysis was performed using SAS software, version 9.1 (SAS Institute, Cary, NC, USA) and R environment software, version 2.12.1 (http://www.r-project.org). Continuous data are expressed as the median and interquartile range (IQR). Chi-square test was used to compare categorical data, and the Mann-Whitney $U$ test was used to compare continuous data. Two-sided $p$ values of $<0.05$ were considered to be statistically significant. Ninety-five percent confidence intervals $(95 \% \mathrm{CI})$ of proportions (including sensitivity, etc.) were calculated with the Wilson score method. ${ }^{28}$ Predictive values were prevalence-adjusted (e.g. $\mathrm{PPV}=$ sensitivity $\times$ prevalence/(sensitivity $\times$ prevalence + $(1-$ specificity $) \times(1-$ prevalence $)))$. The diagnostic value was determined by the area under the curve (AUC) of the receiver operating characteristic (ROC) curve, ${ }^{29}$ and the $95 \%$ confidence limits of the AUCs were determined according to the method of DeLong. ${ }^{30}$ For each POD, the CRP level with the highest Youden's index (equals sensitivity+specificity-1) for the outcome 30-day morbidity was used as cutoff. The same cutoffs were used to determine the diagnostic accuracy for intestinal leaks. The present study was approved by the Swiss Federal Expert Commission for Physician Confidentiality and the local ethics review board.

\section{Results}

Demographics and Clinical Data

Between January 2002 and February 2011, 809 patients underwent LRYGB surgery; however, for 399, no CRP measurements had been performed. After excluding these patients, 410 patients remained for analysis, all with complete clinical data until day 30 after surgery. None of the patients died within 30 days of surgery ( $95 \% \mathrm{CI}, 0-0.9 \%$ ). The overall complication rate for patients included in the study, i.e. those with at least one post-operative CRP measurement, was $18.8 \%$ (77 of 410; $95 \%$ CI, 15.3-22.8\%) including surgery-related and general complications. The rates for each type of complication are summarized in Table 1. Surgery-related complications occurred in 49 of the 410 patients $(12.0 \%$; $95 \% \mathrm{CI}, 9.2-15.5 \%)$, with a median incidence time of 4 days after the surgery (IQR, 2-9 days). Thirty-three patients required surgical revisions within 30 days of surgery $(8.1 \%$; $95 \%$ CI, 5.8-11.1\%).

Intestinal leaks occurred in 17 patients $(4.1 \%$; $95 \% \mathrm{CI}$, 2.6-6.5\%), occurring at a median of 5 days post-operatively (IQR, 4-5 days). Five of the 17 (29.4\%) patients with intestinal leaks were treated conservatively with antibiotics and total parenteral nutrition. One patient additionally needed computed tomography (CT)-guided drainage. Two patients $(11.8 \%)$ were re-operated laparoscopically, and in the remaining ten patients (58.8 \%), a revisional laparotomy was performed. In three patients with intestinal leaks, no upper GI series were performed. One of them directly underwent diagnostic laparoscopy because of the clinical presentation, and in the other two, a CT scan with oral contrast agents was primarily performed. Upper GI series detected

Table 2 Patients characteristics

Data are presented as the median (IQR) and $N(\%)$ $L R Y G B$ laparoscopic Roux-en-Y gastric bypass

${ }^{\mathrm{a} C h i}$-square test

${ }^{\mathrm{b}}$ Mann-Whitney $U$ test

\begin{tabular}{|c|c|c|c|c|c|}
\hline & & \multirow[t]{2}{*}{ Total, $n=410$} & \multicolumn{2}{|c|}{ Surgery-related or general complications } & \multirow[t]{2}{*}{$p$ value } \\
\hline & & & Yes $(n=77)$ & No $(n=333)$ & \\
\hline Gender & $\begin{array}{l}\text { Male } \\
\text { Female }\end{array}$ & $\begin{array}{r}95(23.2 \%) \\
315(76.8 \%)\end{array}$ & $\begin{array}{l}26(33.8 \%) \\
51(66.2 \%)\end{array}$ & $\begin{array}{r}69(20.7 \%) \\
264(79.3 \%)\end{array}$ & $0.014^{\circ}$ \\
\hline \multicolumn{2}{|c|}{ Age (years) } & $44(36-52)$ & $45(38-52)$ & $44(35-52)$ & $0.199^{\mathrm{b}}$ \\
\hline \multicolumn{2}{|c|}{ BMI $\left(\mathrm{kg} / \mathrm{m}^{2}\right)$} & $46(42-50)$ & $45(42-52)$ & $46(42-50)$ & $0.824^{\mathrm{b}}$ \\
\hline \multicolumn{2}{|c|}{ Any additional operation } & $346(84.4 \%)$ & $62(80.5 \%)$ & $284(85.3 \%)$ & $0.299^{\mathrm{a}}$ \\
\hline \multicolumn{2}{|c|}{ Operation time (min) } & $195(153-240)$ & $230(166-280)$ & $185(150-236)$ & $0.002^{\mathrm{b}}$ \\
\hline \multicolumn{2}{|c|}{ Length of hospital stay (days) } & $7(6-8)$ & $8(7-14)$ & $7(6-8)$ & $<0.001^{\mathrm{b}}$ \\
\hline
\end{tabular}


Table 3 Post-operative time course of CRP levels

\begin{tabular}{|c|c|c|c|c|c|c|c|}
\hline & \multicolumn{2}{|c|}{ Total } & \multicolumn{4}{|c|}{ Surgery-related or general complications } & \multirow[t]{3}{*}{$p$ value $^{\mathrm{a}}$} \\
\hline & \multirow[t]{2}{*}{$N$} & \multirow[t]{2}{*}{ CRP (mg/l) } & \multicolumn{2}{|c|}{ Yes } & \multicolumn{2}{|l|}{ No } & \\
\hline & & & $N$ & $\mathrm{CRP}(\mathrm{mg} / \mathrm{l})$ & $N$ & $\mathrm{CRP}(\mathrm{mg} / \mathrm{l}))$ & \\
\hline Pre-operative & 284 & $7(4-12)$ & 45 & $7(4-12)$ & 239 & $7(4-12)$ & 0.945 \\
\hline POD 2 & 61 & $129(80-199)$ & 17 & $229(120-295)$ & 44 & $113(78-173)$ & 0.004 \\
\hline POD 3 & 56 & $110(64-200)$ & 17 & $189(124-275)$ & 39 & $100(62-172)$ & 0.008 \\
\hline POD 4 & 63 & $70(44-121)$ & 22 & $97(72-248)$ & 41 & $55(37-93)$ & 0.003 \\
\hline POD 5 & 42 & $81(38-131)$ & 14 & $112(50-170)$ & 28 & $59(29-123)$ & 0.026 \\
\hline POD 6 & 61 & $51(29-83)$ & 19 & $89(32-213)$ & 42 & $43(24-63)$ & 0.010 \\
\hline POD 7 & 44 & $61(35-105)$ & 18 & $74(51-167)$ & 26 & $46(27-87)$ & 0.010 \\
\hline
\end{tabular}

Data are presented as the median (IQR)

${ }^{a}$ Mann-Whitney $U$ test

the leak in 8 of the 14 patients tested, yielding a sensitivity of $57.1 \%$ (95\% CI, 32.6-78.6\%). For five of these eight patients, CRP measurements between POD 2 and POD 5 were available which all exceeded the cutoff value. Of the six patients with a negative upper GI series, five were tested with a CT scan and oral contrast agent, and in each case, the test result was positive. The remaining patient underwent a diagnostic laparoscopy. For five of the six patients with a false-negative upper GI series, CRP measurements between POD 2 and POD 5 were available. Four of these patients had CRP levels exceeding the cutoff value, while one, measured on POD 3, was below the cutoff.

A total of 32 patients suffered from complications not related to surgery $(7.8 \%$; $95 \% \mathrm{CI}, 5.6-10.8 \%)$, with a median occurrence of 3 days post-operatively (IQR, 17 days). Complications occurred less often in the 399 patients excluded due to lacking CRP measurements, with a significantly lower overall complication rate of $8.5 \%$ (34 of $399 ; 95 \% \mathrm{CI}, 6.2-11.7 \%$; $p<0.001)$ and a significantly lower leakage rate of $0.5 \%$ ( 2 of $399 ; 95 \%$ CI, $0.1-1.8 \%$; $p=0.001)$. Clinical data of patients with and without postoperative complications are summarized in Table 2. Complications were more prevalent in males. Operating time and hospital stay were increased with statistical significance in patients with complications.

\section{Post-Operative Time Course of CRP Levels}

At our institution, CRP levels are routinely measured before surgery. The median CRP serum level before surgery was $7 \mathrm{mg} / \mathrm{l}$ and there was no difference between patients with or without complications (Table 3). On day 2 after surgery, serum CRP increased considerably in all patients; however, for patients with complications, the median CRP level was about double the level of patients without complications
(Table 3). Furthermore, in patients without complications, the CRP levels declined more rapidly than in patients with complications.

\section{Diagnostic Value of CRP Levels}

The AUC of the ROC curve for the 30-day morbidity was between 0.71 and 0.74 for post-operative day 2 to 7 (Fig. 1). Thus, the diagnostic value for the 30-day morbidity was generally low to moderate. The highest sensitivity (100\%) could be observed on POD 5 and 7 and the highest specificity on POD 2 (Table 4). On POD 2, sensitivity was $53 \%$ and specificity was $91 \%$; on POD 3 and POD 4, sensitivity was 76 and $77 \%$ and specificity was 74 and $66 \%$, respectively.

Sensitivity and specificity on day 2 , depending on the CRP threshold, are depicted in Fig. 2. Using the cutoff

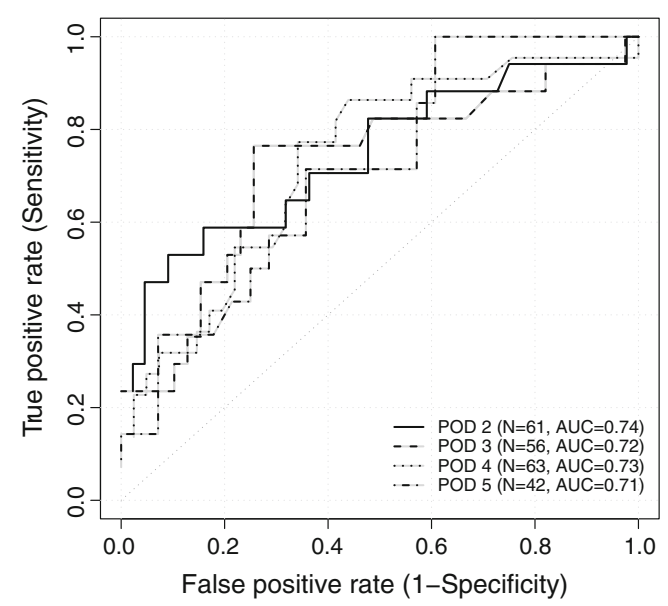

Fig. 1 ROC plots for the diagnostic value of CRP on POD 2 to 5 to detect complications. For each post-operative day, the sensitivity was plotted over the false-positive rate $(1-$ specificity). The dotted diagonal line indicates a purely random test $(\mathrm{AUC}=0.5)$ 


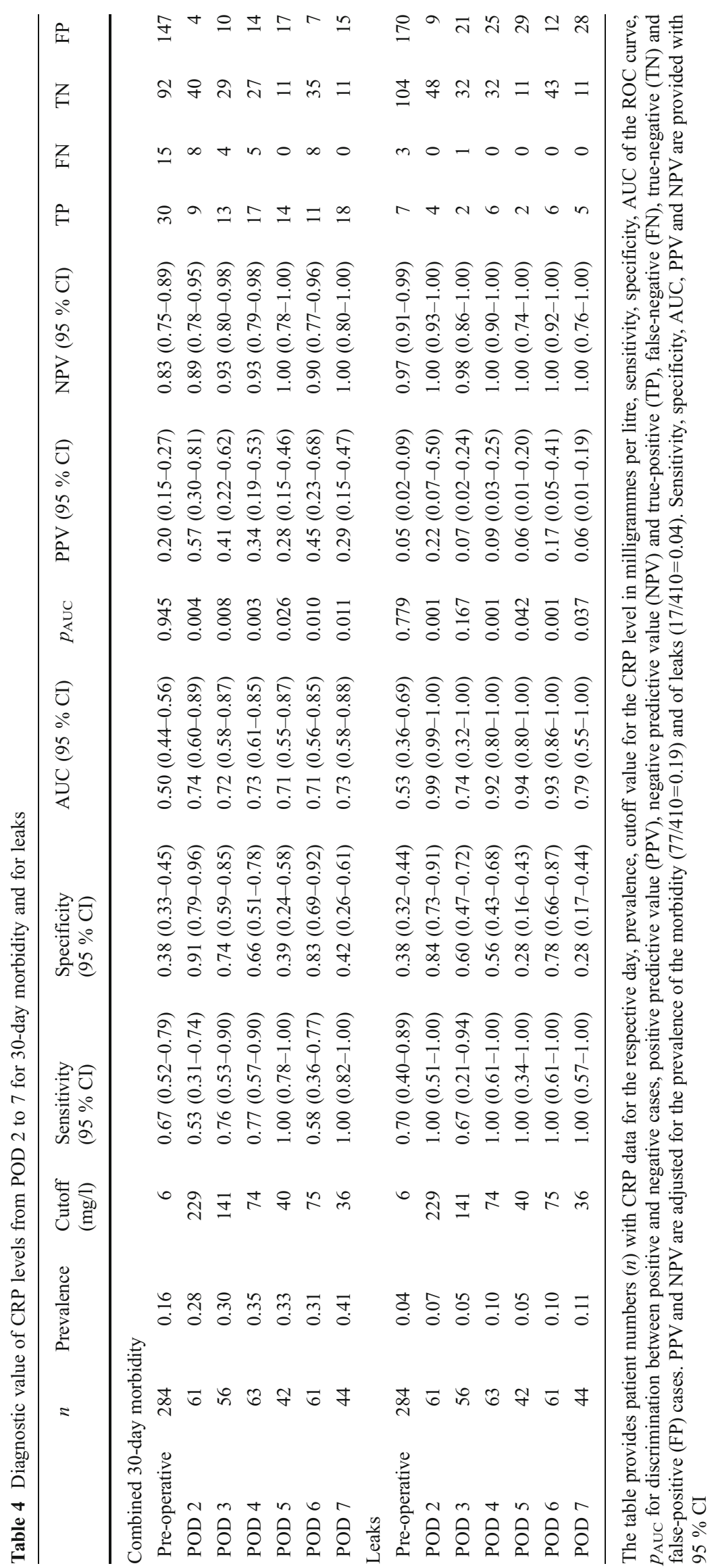




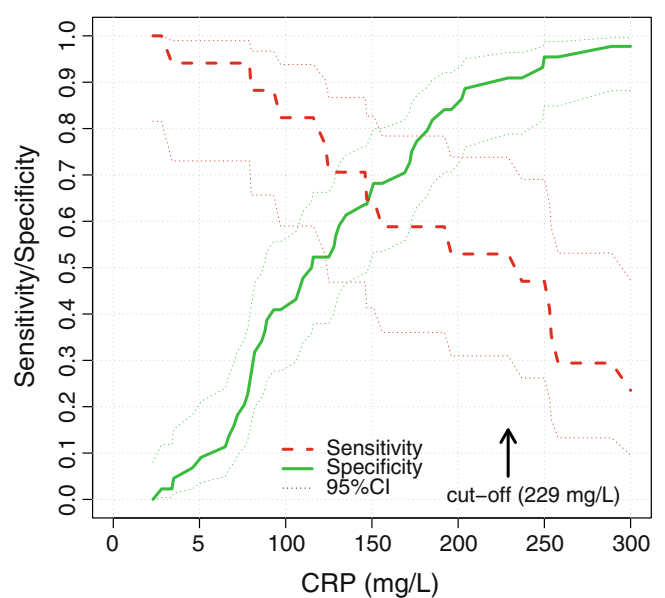

Fig. 2 Influence of threshold on diagnostic values on day 2. Sensitivity and specificity are plotted against the CRP levels on POD 2, together with the $95 \%$ confidence levels (dashed lines). The cutoff level according to the Youden's index is depicted with an arrow

values obtained for the 30-day morbidity, the sensitivity for leaks was $100 \%$ on each POD, except POD 3. Furthermore, all patients with an intestinal leak (diagnosed at POD 3, POD $4(n=2)$ and POD 5) were correctly predicted. However, nine patients were false positively predicted, resulting in specificities of $84,60,56$ and $28 \%$ from POD 2 to POD 5 (Table 4).

\section{Cost-effectiveness of Routine CRP Measurements}

On POD 2, about $80 \%$ of the patients had a CRP level below the cutoff value and none of them developed an anastomotic leak. Thus, radiological imaging could be limited to the $20 \%$ of patients exceeding the cutoff. Assuming $15 €$ per CRP measurement and $400 €$ per radiological imaging, this will result in a saving of $300 €$ per patient.

\section{Discussion}

This study assessed the diagnostic value of CRP for the prediction of early post-operative complications in a large number of patients undergoing LRYGB surgery. On POD 2, the best diagnostic values for general complications and for intestinal leaks were observed. Particularly, the sensitivity for intestinal leaks reached $100 \%$. Based on these results, the upper GI series might be restricted to patients exceeding the CRP cutoff level of $229 \mathrm{mg} / \mathrm{l}$.

The diagnostic value of the upper GI series to detect intestinal leaks after LRYGB surgery is rather low, resulting in far too many false-positive or false-negative results. ${ }^{10-12,14}$ Therefore, some authors have suggested to abandon its routine performance and to restrict radiological examinations to patients with clinical symptoms, like respiratory distress or tachycardia. ${ }^{10,11,15,16}$ Besides lowering costs, such an approach would also spare a large number of patients the exposure to medical radiation associated with an increased lifetime cancer risk. ${ }^{31}$ On the other hand, relying solely on clinical symptoms will occasionally lead to delayed diagnosis of intestinal leaks. ${ }^{2}$ Considering that early detection of postoperative leaks is important to prevent mortality, ${ }^{2,6,7}$ the diagnostic window of a solely clinical-based approach, as described above, might be too wide.

The present study suggests that CRP measurements on POD 2 could potentially overcome this problem. While the CRP level is certainly not specific enough to diagnose an intestinal leak, it appears sufficient to correctly exclude this kind of complication in about $80 \%$ of the patients being at risk. On this background, only the remaining $20 \%$ of patients showing an above cutoff CRP level at POD 2 would have to undergo an upper GI series. Thus, a CRP-based approach could lead to a reduced number of falsely diagnosed patients, to a lower individual radiation exposure and to a considerable cost reduction. While some surgeons might be hesitant to submit a nauseated patient with equivocal findings for a post-operative complication to an upper GI series or a CT scan, we would suggest performing these diagnostic procedures in case of elevated CRP values. While some patients might suffer the discomfort of an unnecessary exam, others would benefit from the early treatment of an impending complication, particularly since nausea can be reduced by antiemetic treatment. If the upper GI series are not part of the routine work-up, CRP levels below the cutoff level might identify patients not at risk of having a leakage or postoperative infectious complication, allowing a safe and early discharge. In contrast, elevated CRP levels should raise suspicion for complication and trigger further diagnostic measures.

Given its great cost-saving potential, the CRP-based approach would even allow for repeated imaging studies in patients with clinical symptoms, while the overall cost would be still lower than with a routine imaging approach. ${ }^{12}$ Furthermore, one may consider to perform a CT scan with oral contrast agents on the selected patients instead of the upper GI series, since this imaging technique is more sensitive to detect leaks. ${ }^{32,33}$

While CRP appears to be valuable in regard to selecting patients for radiological examinations, it is not sufficient to reliably predict general post-operative complications. Here, the best positive predictive value (PPV; on POD 2) was only $57 \%$. Thus, for the diagnosis of general complications, CRP levels obviously need to be interpreted within the context of post-operative clinical symptoms.

In contrast to other studies in which the best diagnostic values for complications were observed on POD 4 or even later, in the present study, the highest diagnostic 
value was already observed on POD $2 .{ }^{17-22}$ It should be noted that these foregoing studies predominantly investigated open surgeries, such as colorectal, gastro-oesophageal and pancreatic operations, and no evidence exists if and how far these findings can be transferred to gastric bypass surgery. Particularly, no evidence exists about lower CRP values after laparoscopic compared to open bypass surgery.

Since there is some evidence that the immunological stress response is weaker after laparoscopic than after open procedures, one could speculate that the post-operative increase of CRP is weaker and CRP levels return more quickly back to normal values after laparoscopy. ${ }^{34-37}$ Supporting this view, in the present study, the average peak CRP level after surgery in patients without complications was $110 \mathrm{mg} / \mathrm{l}$, while in previous studies investigating open surgeries, the respective level was on average $200 \mathrm{mg} / \mathrm{l}$. Also, due to the enhanced surgical trauma, it appears to be impossible to distinguish between a regular post-operative stress response and impending complications upon CRP levels measured at POD 2 and 3 after open surgery. Only after the fourth post-operative day, i.e. when CRP levels usually drop already, CRP levels became diagnostic for complications after open surgery. ${ }^{17-22}$ The present retrospective study provides first evidence that, after laparoscopy, CRP levels can be indicative for impending complications much earlier, i.e. on POD 2. However, prospective trials are clearly needed to ascertain this assumption because it is questionable whether the magnitude and dynamics of CRP levels after different operations in different patients are comparable.

The 30-day morbidity in our series was comparable to previous reports, indicating that our patient population can be considered representative. ${ }^{38-43}$ The median hospital stay was longer than reported in other studies, which is explained by the current hospital policy in Switzerland with reimbursement based on hospital stay rather than diagnosisrelated groups. For a diagnostic study, however, this might actually be favourable since post-operative complications are more reliably diagnosed during hospitalisation than after discharge.

The main limitation of this study is its retrospective design. Nearly half of the patients with a LRYGB operation were not included in the study due to lacking CRP measurements. The lack of CRP measurements could reflect the absence of any clinical symptom prompting such a measurement. In turn, in patients included in the study, the CRP measurement was most likely performed in response to his/her clinical presentation, which could also have biased the time point of measurement. Also, the retrospective design did not allow for evaluating specific clinical parameters with sufficient reliability; thus, symptoms like fever, tachycardia or pain were not assessed in this study.

\section{Conclusion}

In conclusion, the present results suggest that CRP measurements should be routinely performed 2 days after LRYGB surgery in order to exclude impendent complications and leaks in particular. By doing so, radiological imaging examinations for intestinal leaks could be restricted to patients with serum CRP levels above $229 \mathrm{mg} / \mathrm{l}$ on POD 2. If the suggested reliability of this diagnostic approach is confirmed in prospective trials, many patients could be spared from upper GI series, leading to meaningful reduction of health care costs.

\section{References}

1. Ahmed S, Morrow E, Morton J. Perioperative considerations when operating on the very obese: tricks of the trade. Minerva Chirurgica 2010;65:667-676.

2. Ballesta C, Berindoague R, Cabrera M, Palau M, Gonzales M. Management of anastomotic leaks after laparoscopic Roux-en-Y gastric bypass. Obesity Surgery 2008;18:623-630.

3. Rivers E, Nguyen B, Havstad S, Ressler J, Muzzin A, Knoblich B, Peterson E, Tomlanovich M. Early goal-directed therapy in the treatment of severe sepsis and septic shock. N Engl J Med 2001;345:1368-1377.

4. Puskarich MA, Marchick MR, Kline JA, Steuerwald MT, Jones AE. One year mortality of patients treated with an emergency department based early goal directed therapy protocol for severe sepsis and septic shock: a before and after study. Crit Care 2009; 13:R167.

5. Rivers EP (2010) Point: adherence to early goal-directed therapy: does it really matter? Yes. After a decade, the scientific proof speaks for itself. Chest 138:476-480.

6. Fobi MAL, Lee H, Holness R, Cabinda D. Gastric bypass operation for obesity. World Journal of Surgery 1998;22:925-935.

7. Marshall JS, Srivastava A, Gupta SK, Rossi TR, Debord JR. Rouxen-Y gastric bypass leak complications. Archives of Surgery 2003;138:520-523.

8. Serafini F, Anderson W, Ghassemi P, Poklepovic J, Murr MM. The utility of contrast studies and drains in the management of patients after Roux-en-Y gastric bypass. Obesity Surgery 2002;12:34-38.

9. Sims TL, Mullican MA, Hamilton EC, Provost DA, Jones DB. Routine upper gastrointestinal Gastrografin (R) swallow after laparoscopic Roux-en-Y gastric bypass. Obesity Surgery 2003;13:6672.

10. Singh R, Fisher BL. Sensitivity and specificity of postoperative upper GI series following gastric bypass. Obesity Surgery 2003;13:73-75.

11. Doraiswamy A, Rasmussen JJ, Pierce J, Fuller W, Ali MR. The utility of routine postoperative upper GI series following laparoscopic gastric bypass. Surgical Endoscopy and Other Interventional Techniques 2007;21:2159-2162.

12. Carter JT, Tafreshian S, Campos GM, Tiwari U, Herbella F, Cello JP, Patti MG, Rogers SJ, Posselt AM. Routine upper GI series after gastric bypass does not reliably identify anastomotic leaks or predict stricture formation. Surgical Endoscopy and Other Interventional Techniques 2007;21:2172-2177.

13. Shah S, Shah V, Ahmed AR, Blunt DM. Imaging in bariatric surgery: service set-up, post-operative anatomy and complications. British Journal of Radiology 2011;84:101-111. 
14. Hamilton EC, Sims TL, Hamilton TT, Mullican MA, Jones DB, Provost DA. Clinical predictors of leak after laparoscopic Roux-en-Y gastric bypass for morbid obesity. Surgical Endoscopy and Other Interventional Techniques 2003;17:679-684.

15. Lyass S, Khalili TM, Cunneen S, Fujita F, Otsuka K, Chopra R, Lahmann B, Lublin M, Furman G, Phillips EH. Radiological studies after laparoscopic roux-en-Y gastric bypass: Routine or selective? American Surgeon 2004;70:918-921.

16. McCarty TM, Arnold DT, Lamont JP, Fisher TL, Kuhn JA. Optimizing outcomes in bariatric surgery-Outpatient laparoscopic gastric bypass. Annals of surgery 2005;242:494-501.

17. Welsch T, Muller SA, Ulrich A, Kischlat A, Hinz U, Kienle P, Buchler MW, Schmidt J, Schmied BM. C-reactive protein as early predictor for infectious postoperative complications in rectal surgery. Int J Colorectal Dis 2007;22:1499-1507.

18. Welsch T, Frommhold K, Hinz U, Weigand MA, Kleeff J, Friess $\mathrm{H}$, Buchler MW, Schmidt J. Persisting elevation of C-reactive protein after pancreatic resections can indicate developing inflammatory complications. Surgery 2008;143:20-28.

19. Korner H, Nielsen HJ, Soreide JA, Nedrebo BS, Soreide K, Knapp JC. Diagnostic accuracy of C-reactive protein for intraabdominal infections after colorectal resections. J Gastrointest Surg 2009;13:1599-1606.

20. Montagnana M, Minicozzi AM, Salvagno GL, Danese E, Cordiano C, De Manzoni G, Guidi GC, Lippi G. Postoperative variation of C-reactive protein and procalcitonin in patients with gastrointestinal cancer. Clin Lab 2009;55:187-192.

21. Ortega-Deballon P, Radais F, Facy O, d'Athis P, Masson D, Charles PE, Cheynel N, Favre JP, Rat P. C-reactive protein is an early predictor of septic complications after elective colorectal surgery. World J Surg 2010;34:808-814.

22. Dutta S, Fullarton GM, Forshaw MJ, Horgan PG, McMillan DC. Persistent elevation of C-reactive protein following esophagogastric cancer resection as a predictor of postoperative surgical site infectious complications. World J Surg 2011;35:1017-1025.

23. Chromik AM, Endter F, Uhl W, Thiede A, Reith HB, Mittelkotter U. Pre-emptive antibiotic treatment vs 'standard' treatment in patients with elevated serum procalcitonin levels after elective colorectal surgery: a prospective randomised pilot study. Langenbecks Arch Surg 2006;391:187-194.

24. Simon L, Gauvin F, Amre DK, Saint-Louis P, Lacroix J. Serum procalcitonin and C-reactive protein levels as markers of bacterial infection: a systematic review and meta-analysis. Clin Infect Dis 2004;39:206-217.

25. Sponholz C, Sakr Y, Reinhart K, Brunkhorst F. Diagnostic value and prognostic implications of serum procalcitonin after cardiac surgery: a systematic review of the literature. Crit Care 2006;10:R145.

26. NIH conference (1991) Gastrointestinal surgery for severe obesity. Consensus Development Conference Panel. Ann Intern Med 115:956-961.

27. Consensus über die Behandlung der Adipositas in der Schweiz 1999. Schweiz Med Wochenschr 2011;129:S4-S20.

28. Agresti A, Coull BA. Approximate is better than "exact" for interval estimation of binomial proportions. Am Stat 1998;52:119-126.
29. Hanley JA, McNeil BJ. The meaning and use of the area under a receiver operating characteristic (ROC) curve. Radiology 1982;143:29-36.

30. DeLong ER, DeLong DM, Clarke-Pearson DL. Comparing the areas under two or more correlated receiver operating characteristic curves: a nonparametric approach. Biometrics 1988;44:837845.

31. Oei TN, Shyn PB, Govindarajulu U, Flint R. Diagnostic medical radiation dose in patients after laparoscopic bariatric surgery. Obes Surg 2010;20:569-573.

32. Yu JX, Turner MA, Cho SR, Fulcher AS, DeMaria EJ, Kellum JM, Sugerman HJ. Normal anatomy and complications after gastric bypass surgery: Helical CT findings. Radiology 2004;231:753760.

33. Carucci LR, Turner MA. Radiologic evaluation following Rouxen-Y gastric bypass surgery for morbid obesity. European Journal of Radiology 2005;53:353-365.

34. Burpee SE, Kurian M, Murakame Y, Benevides S, Gagner M. The metabolic and immune response to laparoscopic vs open liver resection. Surgical Endoscopy and Other Interventional Techniques 2002;16:899-904.

35. Grande M, Tucci GF, Adorisio O, Barini A, Rulli F, Neri A, Franchi F, Farinon AM. Systemic acute-phase response after laparoscopic and open cholecystectomy. Surgical Endoscopy and Other Interventional Techniques 2002;16:313-316.

36. Karayiannakis AJ, Makri GG, Mantzioka A, Karousos D, Karatzas G. Systemic stress response after laparoscopic or open cholecystectomy: A randomized trial. British Journal of Surgery 1997;84:467471.

37. Nguyen NT, Goldman CD, Ho HS, Gosselin RC, Singh A, Wolfe BM. Systemic stress response after laparoscopic and open gastric bypass. Journal of the American College of Surgeons 2002;194:557566.

38. Mognol P. Laparoscopic conversion of laparoscopic gastric banding to Roux-en-Y gastric bypass: A review of 90 patients. Obesity Surgery 2006;16:1028

39. Owens BM, Owens ML, Hill CW. Effect of revisional bariatric surgery on weight loss and frequency of complications. Obesity Surgery 1996;6:479-484.

40. Riele WWT, Sze YK, Wiezer MJ, van Ramshorst B. Conversion of failed laparoscopic gastric banding to gastric bypass as safe and effective as primary gastric bypass in morbidly obese patients. Surgery for Obesity and Related Diseases 2008;4:735739 .

41. Topart P, Becouarn G, Ritz P. One-year weight loss after primary or revisional Roux-en-Y gastric bypass for failed adjustable gastric banding. Surgery for Obesity and Related Diseases 2009;5:459462.

42. Tucker O, Sucandy I, Szomstein S, Rosenthal RJ. Revisional surgery after failed laparoscopic adjustable gastric banding. Surgery for Obesity and Related Diseases 2008;4:740-747.

43. Zingg U, McQuinn A, DiValentino D, Kinsey-Trotman S, Game P, Watson D. Revisional vs. primary Roux-en-Y gastric bypass - a case-matched analysis. Obes Surg 2010;20:1627-1632. 